Abstracta Iranica Abstracta Iranica

Revue bibliographique pour le domaine irano-aryen

Volume 42-43 | 2021

Comptes rendus des publications de 2019-2020

\title{
Christopher Markiewicz. The Crisis of Kingship in Late Medieval Islam: Persian Emigres and the Making of Ottoman Sovereignty
}

Yoan Parrot

\section{(2) OpenEdition \\ Journals}

Édition électronique

URL : https://journals.openedition.org/abstractairanica/53602

DOI : $10.4000 /$ abstractairanica. 53602

ISSN : 1961-960X

Éditeur :

CNRS (UMR 7528 Mondes iraniens et indiens), Éditions de l'IFRI

Référence électronique

Yoan Parrot, "Christopher Markiewicz. The Crisis of Kingship in Late Medieval Islam: Persian Emigres and the Making of Ottoman Sovereignty », Abstracta Iranica [En ligne], Volume 42-43 | 2021, document 1, mis en ligne le 30 décembre 2021, consulté le 13 décembre 2022. URL : http://journals.openedition.org/ abstractairanica/53602 ; DOI : https://doi.org/10.4000/abstractairanica.53602

Ce document a été généré automatiquement le 13 décembre 2022.

Tous droits réservés 


\title{
Christopher Markiewicz. The Crisis of Kingship in Late Medieval Islam: Persian Emigres and the Making of Ottoman Sovereignty
}

\author{
Yoan Parrot
}

\section{RÉFÉRENCE}

Christopher Markiewicz. The Crisis of Kingship in Late Medieval Islam: Persian Emigres and the Making of Ottoman Sovereignty. Cambridge : Cambridge University Press, 2019, 345 p. ISBN : 978-1-108-71057-2

1 L'auteur, spécialiste d'histoire politique et intellectuelle ottomane à l'université de Birmingham, livre dans cette étude très documentée la biographie d'un savant persan, Idris Bidlisi (1457-1520). Cette biographie lui sert de prétexte pour dresser un panorama des évolutions idéologiques depuis l'Iran timouride et aq-qoyunlu jusqu'à l'Anatolie ottomane à la charnière des $\mathrm{XV}^{\mathrm{e}}$ et $\mathrm{XVI}^{\mathrm{e}}$ siècles à travers une question centrale : qu'est-ce qui dans ce $\mathrm{XV}^{\mathrm{e}}$ siècle fragmenté territorialement et politiquement a pu permettre l'émergence d'empires musulmans territorialement définis et idéologiquement affirmés au XVI ${ }^{\mathrm{e}}$ siècle (p.3) ? À travers cette question, il développe l'idée maîtresse de son ouvrage selon laquelle les savants persans, parmi lesquels Bidlisi, ont réinvesti des concepts politiques anciens pour les appliquer aux souverains de leur époque et joué un rôle déterminant dans la diffusion du vocabulaire timouride de la souveraineté à travers le monde musulman oriental.

2 L'ouvrage est divisé en deux parties. La première (p. 23-147) porte sur l'itinéraire politique d'Idris Bidlisi, son parcours dans les administrations et les cours aq qoyunlu puis ottomane dans un contexte de construction impériale. L'auteur explique les influences idéologiques dont il a hérité et qu'il contribue à diffuser, en particulier son 
concept central de Hilafat-i rahmani (vice-régence de Dieu) qui sert à justifier, sous l'influence de différents courants messianiques, une légitimité issue directement de Dieu. La deuxième partie (p. 149-291) constitue une approche historique de la philosophie politique islamique depuis le XIII ${ }^{e}$ siècle qui cherche notamment à comprendre l'origine des titulatures et concepts anciens (notamment ceux de șāhib qirān et mujaddid) adaptés pour les souverains du $\mathrm{XV}^{\mathrm{e}}$ siècle. C'est l'occasion pour l'auteur d'évoquer les innovations idéologiques timourides et leurs circulations par des moyens variés par le biais des savants persans jusqu'aux Ottomans. Une chronologie synthétique de la vie de Bidlisi est donnée en appendice (p. 292-295) de même qu'une très pratique recension complète des manuscrits des travaux de Bidlisi connus, avec leur cote et leur localisation (p. 297-304). Une bibliographie fournie et à jour (p. 305-334) ainsi qu'un index (p. 335-345) complètent l'ouvrage.

Cette étude vient compléter utilement des travaux similaires d'Evrim Binbaş sur les réseaux savants timourides (Intellectual networks in Timurid Iran, Sharaf al-Dīn Yazdī and the Islamicate Republic of Letters, 2016). L'auteur nous permet au fond d'approcher l'importance du corpus idéologique persan dans la construction de l'idéologie impériale universelle du sultanat ottoman et sa stabilisation au XVI ${ }^{e}$ siècle.

\section{AUTEURS}

\section{YOAN PARROT}

Doctorant Université d'Aix-Marseille 